International Journal of Soft Computing 7 (5): 256-263, 2012

ISSN: $1816-9503$

(C) Medwell Journals, 2012

\title{
Emission/Economic Load Dispatch Using Combination of Evolutionary Algorithms
}

\author{
Attia A. El-Fergany and Mahdi El-Arini \\ Department of Electric Power and Machine, Faculty of Engineering, \\ Zagazig University, Zagazig, Egypt
}

\begin{abstract}
This study presents an integrating Genetic Algorithm (GA) and Pattern Search (PS) approaches to solve the Combined Emission/Economic Dispatch (CEED) problems with multi-objectives have been developed. This integration will combine the strengths of GA and PS to solve this problem. The PS performance is highly dependent on the initial/starting point. To tackle this issue, GA was utilized to initiate the starting point for PS and to validate the obtained result of PS as well. The weighted multi-objective function with penalty factor is used in this study. The proposed weighting factor plays significant part on the problem solution. The proposed methodology considers operational power constraints of generating units, value-point loading ripple effects with non-convex characteristics and line losses as well for practical applications. The proposed integrating algorithms were intensively demonstrated, tested and verified on several cases. The obtained results prove high quality and effectiveness of proposed integrated GA-PS algorithm to solve CEED problems with reduced execution time.
\end{abstract}

Key words: Emission, evolutionary algorithms, load dispatch, mutli-objective function, Egypt

\section{INTRODUCTION}

Operating at absolute minimum cost can no longer be the only criterion for dispatching electric power due to increasing concern of the environmental considerations (Anonymous, 1991). Now a days, the Economic Emission Dispatch (EED) assumes a lot of significance to meet the clean energy requirements of the society while at the same time minimizing the cost of generation. Energy sources to produce mechanical power applied to the rotor shaft of generating units are of fossil fuels. This can cause a vast amount of carbon dioxide $\left(\mathrm{CO}_{2}\right)$, sulfur dioxide $\left(\mathrm{SO}_{2}\right)$ and nitrogen oxides $\left(\mathrm{NO}_{\mathrm{z}}\right)$ emissions in which atmospheric pollution is created (Gent and Lamont, 1971; Talaq et al., 1994).

The characteristics of emissions of different pollutants are different and are usually highly non-linear. The primary objective of this problem is to determine the most economic loadings of the generators such that the load demands in the intervals of the generation scheduling horizon can be met and the operation constraints of the generators are satisfied and minimizing the total emissions. Past decades, conventional optimization techniques such as Lagrangian Relaxation Method, Linear Programming, Quadratic Programming, the Gradient Method and Dynamic Programming have been successfully used to solve power system optimization problems (Talaq et al., 1994; Lee and El-Sharkawi, 2008;
Bansal, 2005; Zhu, 2009). Recently, there is an upsurge in the use of modern evolutionary computing techniques in the field of power system optimizations. The methods based on Artificial Neural Network (ANN) and Heuristic Search (HS) techniques based solution methodologies have been applied to solve emission economic dispatch problems. The Genetic Algorithm (GA) Method, Evolutionary Programming (EP), Evolution Strategy (ES), Tabu Search (TS) and Simulated Annealing (SA) are some of the well known Evolutionary algorithms (Lee andEl-Sharkawi, 2008; Bansal, 2005; Zhu, 2009) and related fields such as Swarm Intelligence (Ant Colony Optimization (ACO), Bee Colony Optimization (BCO), Cat Swarm Optimization (CSO), Glowworm Swarm Optimization (GSO)/Fireflies Algorithm (FA) and Particle Swarm Optimization (PSO)) are suited to deal with the problem at hand because of their ability to find the solution near global optimal (Zhu, 2009).

Pao-La-Or et al. (2010), Pitono et al. (2009), Chaturvedi et al. (2008) and Thakur et al. (2006) PSO algorithm used to solve the problem of combined economic and emission dispatch. Penalty factors are defined which blendthe emission costs with the fuel costs. New and simple recursive approaches were applied and introduced to solve emission constrained dispatch problem (Muralidharan et al., 2006; Balamurugan and Subramanian, 2007). An ANN based solution for CEED problem has been reported (Kumarappan et al., 2002). The

Corresponding Author: Attia A. El-Fergany, Department of Electric Power and Machine, Faculty of Engineering, 
solution methodology using Hopfield Network Model had been suggested (King et al., 1995). GA and EP have been successfully applied to find the economic schedule of generation for CEED problems (Song et al., 1997; Guvenc, 2010; Basu, 2007; Venkatesh et al., 2003). SA is the stochastic optimization technique has been applied to find the solution of emission economic dispatch problems (Sasikala and Ramaswamy, 2010; Basu, 2005). An improved TS algorithm to Economic Emission Dispatch with Transmission Line Constraint was introduced (Senthil and Manikandan, 2010). Abido (2006, 2003), King et al. (2006) and Yokoyama et al. (1988) suggested and discussed the novel multi-objective to solve CEED problem subjected to variety of constraints. More details about GA have been presented by Goodman (2007) and Mitchell (1998). GA compared to traditional optimization methods can be listed as follows:

- GA seeks a number of candidate solutions in parallel and does not start from a single point

- GA uses probabilistic transition rules using GA operators rather than deterministic ones

- GA may use an encoding of the parameter set instead of the parameter itself

- GA does not require derivative information or other auxiliary knowledge except objective or fitness functions

- GA provides a high probability of finding the near global optimum

- GA is capable of coping with various problems and difficulties such as non-linearity, non-smoothness, discontinuity and non-convex characteristics

Due to these attractive properties, GA has become very popular for use in various power system optimization applications. A comprehensive review of direct and pattern search can be found by Audet and Dennis (2003), Kolda et al. (2003) and Al-Sumait etal. (2007) where a broader class of methods referred to as generating set search is described. The Hybrid PS Method that incorporates a GA in start process for initiating the starting point and at final stage for validating the obtained solution by PS Method has been introduced in this study.

This research presents the solution of the environmental economic dispatch problems using integration of GA and PS in order to help each other overcome their problems to obtain the best results in the shortest time. The contradicting bi-objectives are simultaneously minimized through the provision of the weighting factor and penalty factor. CEED has been proposed in the field of power generation dispatch which simultaneously minimizes both fuel cost and total emissions. When the emission is minimized the fuel cost may be unacceptably high or when the fuel cost is minimized the emission may be high. The environmental/economic dispatch involves the simultaneous optimization of fuel cost and emission objectives which are conflicting ones.

\section{PROPOSED ENVIRONMENTAL ECONOMIC DISPATCH MODELLING}

\section{The mathematical model of the problem needs}

Objective function: The Economic Load Dispatch (ELD) problem can be formulated mathematically as a constrained optimization problem with an objective function of the form as shown in Eq. 1. Objective function:

$$
\text { Minimize: } \mathrm{FC}_{\mathrm{T}}=\sum_{\mathrm{i}=1}^{\mathrm{N}} \mathrm{FC}_{\mathrm{i}}\left(\mathrm{P}_{\mathrm{i}}\right)
$$

And:

$$
\mathrm{FC}_{\mathrm{i}}\left(\mathrm{P}_{\mathrm{i}}\right)=\mathrm{a}_{\mathrm{i}} \mathrm{P}_{\mathrm{i}}^{2}+\mathrm{b}_{\mathrm{i}} \mathrm{P}_{\mathrm{i}}+\mathrm{c}_{\mathrm{i}}
$$

Where:

$\mathrm{FC}_{\mathrm{T}}=$ The total generation cost

$\mathrm{N}=$ The total number of generating units

$\mathrm{FC}_{\mathrm{i}}=$ The power generation cost function of the ith unit

$P_{i}=$ The power of the ith generating unit

$\mathrm{a}_{\mathrm{i}}-\mathrm{c}_{\mathrm{i}}=$ The fuel cost coefficients of the ith generating unit

The Cost Function $\left(\mathrm{FC}_{\mathrm{i}}\right)$ should be modified to consider the valve-point effects as shown in Fig. 1. Typically, the valve point results in as each steam valve starts to open the ripples to be taken into account for the valve-point effects, sinusoidal functions are added to the quadratic cost functions as follows in Eq. 3:

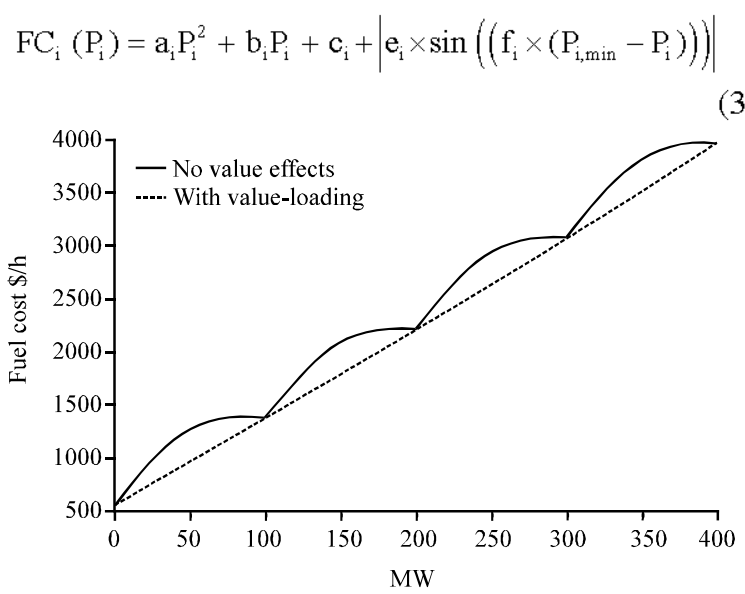

Fig. 1: Fuel cost function with and without valve-effects 
Where:

$\mathrm{P}_{\mathrm{i}, \mathrm{min}}=$ The minimum power output of generator (i)

$\mathrm{a}_{\mathrm{i}}-\mathrm{c}_{\mathrm{i}}=$ The cost coefficients of generator (i)

$\mathrm{e}_{\mathrm{i}}, \mathrm{f}_{\mathrm{i}}=$ Reflecting valve-point effects

On the other side, the pollutant emission dispatch problem can be described as the optimization of total amount of pollutant emission such as sulphur dioxide, $\mathrm{SO}_{2}$ and nitrogen oxides, $\mathrm{NO}_{\mathrm{z}}$ caused by burning of fuel in thermal defined by the following illustrated in Eq. 4 (Song et al., 1997):

$$
\left.\mathrm{E}_{\mathrm{T}}=\sum_{\mathrm{i}=1}^{\mathrm{N}} \alpha_{\mathrm{i}} \mathrm{P}_{\mathrm{i}}^{2}+\beta_{\mathrm{i}} \mathrm{P}_{\mathrm{i}}+\gamma_{\mathrm{i}}+\xi_{\mathrm{i}} \mathrm{e}^{\tau_{\mathrm{i}} \mathrm{P}_{\mathrm{i}}}\right)
$$

Where:

$\mathrm{E}_{\mathrm{T}} \quad=$ The total pollutant emission $(\mathrm{kg} / \mathrm{h})$

$\mathrm{P}_{\mathrm{i}} \quad=$ The power output of generating unit $\mathrm{i}$

$\alpha_{\mathrm{i}}, \beta_{\mathrm{i}}, \gamma_{\mathrm{i}}, \xi_{\mathrm{i}}, \tau_{\mathrm{i}}=$ Emission coefficients of unit $\mathrm{i}$

Weighted sum CEED: To transform a multi-objective optimization problem into a single objective, weighted sum and utility method is often used. There are so many ways to construct the weighted sum function and there is not any easy guideline to choose which form is the best for a given problem. The choice of weighting coefficient is essentially to assign a preference order by the decision maker to the multi-objectives. The economic dispatch and emission dispatch are two different problems. Emission dispatch can be included in conventional economic load dispatch problems by adding an emission constraint into the problem. In this study, the two objectives can be converted into a single objective function (Muralidharan et al., 2006; Balamurugan and Subramanian, 2007) by introducing a price penalty factor as illustrated in Eq. 5 as defined follows:

$$
h_{i}=\frac{F_{i}\left(P_{i}^{\max }\right)}{E_{i}\left(P_{i}^{\max }\right)}
$$

The price penalty factor blends the emission with fuel cost and is defined as the ratio between the maximum fuel cost and maximum emission of the corresponding generator. The bi-objective CEED problem is converted into single weighted optimization problem with introducing a price penalty factor $h_{i}$ (Eq. 6):

$$
\operatorname{Min}\left(\mathrm{F}_{\mathrm{T}}\right)=\sum_{\mathrm{i}=1}^{\mathrm{N}}\left(\mathrm{W} \cdot \mathrm{FC}_{\mathrm{i}}+(1-\mathrm{W}) \cdot \mathrm{h}_{\mathrm{i}} \cdot \mathrm{E}_{\mathrm{i}}\right)
$$

where, the value of $W(0 \leq W \leq 1)$ shows the importance of the two parts of the multi-objective function w.r.t. each other.
Equality and inequality constraints: The main constraints which are considered in this study are given equality constraint (Power balance constraint):

$$
\sum_{i=1}^{N} P_{i}=P_{D t}+P_{L o s s}
$$

Where:

$\mathrm{P}_{\mathrm{Dt}}=$ The total system load demand

$\mathrm{P}_{\text {Loss }}=$ The total line losses

$\mathrm{P}_{\text {Loss }}$ can be calculated using Eq. 8:

$$
P_{\text {Loss }}=\sum_{i=1}^{N} \sum_{j=1}^{N} P_{i}^{T} B_{i j} P_{j}+\sum_{i=1}^{N} P_{i} B_{o i}+B_{o o}
$$

Where:

$\mathrm{B}_{\mathrm{ij}}, \mathrm{B}_{0 \mathrm{i}}$ and $\mathrm{B}_{00}=$ Transmission line loss coefficients

$\mathrm{P}_{\mathrm{i}}^{\mathrm{T}} \quad=$ Vector transpose of all generation plants net MW

$\mathrm{B}_{\mathrm{ij}} \quad=$ Square matrix of same dimension as $\mathrm{P}_{\mathrm{i}}$

$\mathrm{B}_{\mathrm{oi}} \quad=$ Vector of same length as $\mathrm{P}_{\mathrm{i}}$

$\mathrm{B}_{00} \quad=$ Constant

Inequality constraints (Generation limits) which is shown as:

$$
\mathrm{P}_{\mathrm{i}, \min } \leq \mathrm{P}_{\mathrm{i}} \leq \mathrm{P}_{\mathrm{i}, \max } \text { for } \mathrm{i}=1,2, \ldots, \mathrm{N}
$$

where, $P_{i, \min }$ and $P_{i, \max }$ are the $\min / \max$ power outputs of generator i. Finally, the mathematical model is summarized as:

$$
\operatorname{Min}\left\{\mathrm{FT}\left(\mathrm{P}_{\mathrm{i}}, \mathrm{W}\right)\right\}
$$

Subjected to:

$$
\begin{aligned}
& \sum_{i=1}^{N} P_{i}=P_{D t}+P_{L o s s} \\
& P_{i, \text { min }} \leq P_{i} \leq P_{i, \text { max }}
\end{aligned}
$$

\section{PROPOSED INTEGRATION BETWEEN GA AND PS}

GA is a stochastic optimization method which starts from multiple points to obtain a solution but it provides only a near global solution. In addition, it is not easy to regulate a GA convergence. Tuning global parameters such as population size, mutation probability and crossover probability has been the most recommended technique for control-ling premature convergence in the GA. A generally effective method for setting parameters has not yet been demonstrated. Ideal parameters are likely problem-dependent. 
On the other hand, PS searches from a single point to obtain a solution. However, the solution obtained from PS is normally a local optimum solution. Therefore, in order to obtain a high quality solution the two parts method, comprising both GA and PS is proposed in this study. In the proposed method, after the specified termination criteria for the GA is reached using default option of MATLAB (http://www.mathworks.com) without any fine tune for parameters, PS is applied in the second part by using the solution from GA as an initial point to obtain a solution which is closer to the global solution. Finally, the solution obtained by PS is passed to GA for validation. The flow chart of the integration process is shown in Fig. 2.

The hybrid PS Method that incorporates a GA in start process for initiating the starting point and at final stage for validating the obtained solution by PS Method has been introduced in this study. The idea is to start GA with an initial random population with default settings (no need to consume lot of time for fine tuning of the GA parameters) to create new starting/initial point to be utilized by PS as the performance of PS is highly dependable on the starting point. Hence, the problem is tackled using both deterministic and stochastic approaches of different complexities. GA doesn't start the solution with a start point as PS does. GA starts to operate with more solutions compared to a starting population randomly created by taking determined objective function variables into consideration.

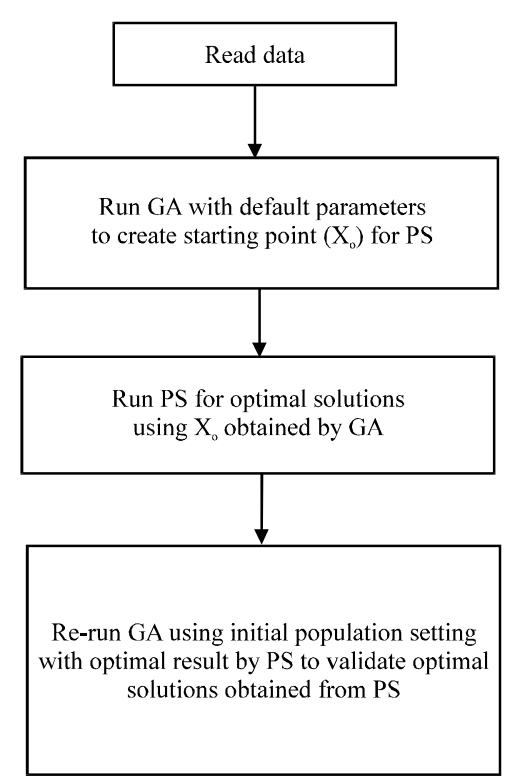

Fig. 2: Integration process of GA-PS
A set of MATLAB files, incorporated in the optimization toolbox, implementing the proposed PS and integrated GA-PS approaches have been used to solve various CEED problems with different study modes. Thus, the combined objective function for all test cases has been coded in MATLAB environment. The following parameters were needed for data input:

- Minimal and maximal power outputs of each unit

- B-matrix of line losses

- Coefficients of unit fuel cost function including coefficients of valve-point loading

- Emission coefficients

- Total load demand

The objective function, equality and inequality constraints were written in MATLAB m-files. The ranges for the variables were set in MATTLAB 7.12 Version release $2011 \mathrm{a}$ (http://www.mathworks.com).

\section{NUMERICAL SIMULATIONS AND COMPARISONS}

To verify the feasibility and efficiency of applying PS and integrated GA-PS to solve the environmental economic dispatch problem based on the proposed mathematical model and the proposed combination of GA and PS, several cases were tested compared and investigated. Among of these, two cases will be presented. The PS and GA-PS based algorithms are applied to solve the six-units with and without line losses (for sake of comparisons, neglecting effects of valve-loading) as illustrated in Case I. In Case II, the algorithms were applied to eleven-generator system with neglecting line losses. Simulations were carried out using Optimization Toolbox of MATLAB ${ }^{\boxplus} 7.12$ release $2011 \mathrm{a}$ version and executed on a LAPTOP with Processor Intel ${ }^{\circledR}$ Core i5 CPU $2.40 \mathrm{GHz}$ with a $4.0 \mathrm{~GB}$ of RAM with 32-bit operating system.

Case I: 6-Generating Unit's System: Fuel cost coefficients and generation limits for each generating unit of the test system were given in Table 1. Table 2 shown pollutant emission coefficients of each generating unit.

Table 1: Fuel cost coefficients with capacity constrains neglecting ripple effects of valves

\begin{tabular}{|c|c|c|c|c|c|}
\hline Units & $\begin{array}{c}\mathrm{a}_{\mathrm{i}} \\
\left(\$ /\left(\mathrm{MW}^{2} \mathrm{~h}\right)\right)\end{array}$ & $\begin{array}{c}\mathrm{b}_{\mathrm{i}} \\
(\$ /(\mathrm{MWh}))\end{array}$ & $\begin{array}{c}\mathrm{c}_{\mathrm{i}} \\
(\$ / \mathrm{h})\end{array}$ & $\begin{array}{l}\mathrm{P}_{\mathrm{imin}} \\
(\mathrm{MW})\end{array}$ & $\begin{array}{l}\mathrm{P}_{\mathrm{i}, \max } \\
\text { (MW) }\end{array}$ \\
\hline$\overline{\mathrm{G}_{1}}$ & 0.15247 & 38.53973 & 756.79886 & 10 & 125 \\
\hline $\mathrm{G}_{2}$ & 0.10587 & 46.15916 & 451.32513 & 10 & 150 \\
\hline $\mathrm{G}_{3}$ & 0.02803 & 40.39655 & 1049.9977 & 35 & 225 \\
\hline $\mathrm{G}_{4}$ & 0.03546 & 38.30553 & 1243.5311 & 35 & 210 \\
\hline $\mathrm{G}_{5}$ & 0.02111 & 36.32782 & 1658.5696 & 130 & 325 \\
\hline$\underline{\mathrm{G}}_{6}$ & 0.01799 & 38.27041 & 1356.6592 & 125 & 315 \\
\hline
\end{tabular}




\section{The B-coefficients loss matrix:}

$$
\mathrm{B}=1 \mathrm{e}^{-3} \times\left(\begin{array}{cccccc}
0.1400 & 0.0170 & 0.0150 & 0.0190 & 0.0260 & 0.0220 \\
0.0170 & 0.0600 & 0.0130 & 0.0160 & 0.0150 & 0.0200 \\
0.0150 & 0.0130 & 0.0650 & 0.0170 & 0.0240 & 0.0190 \\
0.0190 & 0.0160 & 0.0170 & 0.0710 & 0.0300 & 0.0250 \\
0.0260 & 0.0150 & 0.0240 & 0.0300 & 0.0690 & 0.0320 \\
0.0220 & 0.0200 & 0.0190 & 0.0250 & 0.0320 & 0.0850
\end{array}\right)
$$

The obtained results for the 6 Unit System using PS only and proposed GA-PS for power demand of

\begin{tabular}{|c|c|c|c|}
\hline Units & $\alpha_{I}\left(\mathrm{~kg} /\left(\mathrm{MW}^{2} \mathrm{~h}\right)\right)$ & $\beta_{\mathrm{i}}(\mathrm{kg} /(\mathrm{MWh}))$ & $\gamma_{i}(\mathrm{~kg} / \mathrm{h})$ \\
\hline $\mathrm{G}_{1}$ & 0.00419 & 0.327670 & 13.85932 \\
\hline $\mathrm{G}_{2}$ & 0.00419 & 0.327670 & 13.85932 \\
\hline $\mathrm{G}_{3}$ & 0.00683 & -0.54551 & 40.26690 \\
\hline $\mathrm{G}_{4}$ & 0.00683 & -0.54551 & 40.26690 \\
\hline $\mathrm{G}_{5}$ & 0.00461 & -0.51116 & 42.89553 \\
\hline $\mathrm{G}_{6}$ & 0.00461 & -0.51116 & 42.89553 \\
\hline
\end{tabular}

$500 \mathrm{MW}$ without and with line losses were given in Table 3 and 4, respectively. It showed that the both algorithms succeeded in finding a global optimal solution or near optimal solution for 3 modes of study for $\mathrm{W}=0$, $\mathrm{W}=1$ or $\mathrm{W}=0.5$ with relaxing all equality and inequality constraints. It is self-explanatory that the obtained results are matched by both methods. However, the execution time for the hybrid GA-PS is very completive and superior compared with using the PS only. PS algorithm is highly dependable on the starting point used to get the optimal or near optimal solution. As shown in Table 5 and 6 (CEED study mode with Weight $=0.5$ ) in comparisons between obtained recent results (Muralidharan et al., 2006; Balamurugan and Subramanian, 2007; Guvenc, 2010; Sasikala and Ramaswamy, 2010) that both PS and proposed integrated GA-PS were succeeded to obtain very competitive solutions in very short time compared with SA that was able to get solution in $23.5 \mathrm{sec}$ (Sasikala and Ramaswamy, 2010). The average execution

Table 3: Optimal scheduling of 6-generator by PS only and proposed GA-PS (No losses) with $\mathrm{P}_{\text {Demand }}=500 \mathrm{MW}$

\begin{tabular}{|c|c|c|c|c|c|c|}
\hline \multirow[b]{2}{*}{ Unit/Study mode } & \multicolumn{2}{|c|}{ Best fuel $(W=1)$} & \multicolumn{2}{|c|}{ Best emission $(W=0)$} & \multicolumn{2}{|c|}{ CEED $(W=0.5)$} \\
\hline & PS & GA-PS & PS & GA-PS & PS & GA-PS \\
\hline$\overline{\mathrm{P}_{\mathrm{G} 1}(\mathrm{MW})}$ & 17.3990 & 17.3988 & 35.9318 & 35.9318 & 19.9768 & 19.9769 \\
\hline $\mathrm{P}_{\mathrm{C}_{2}}$ (MW) & 10.0000 & 10.0000 & 35.9316 & 35.9318 & 14.8731 & 14.8730 \\
\hline $\mathrm{P}_{\mathrm{G3} 3}(\mathrm{MW})$ & 61.5468 & 61.5471 & 86.5684 & 86.5682 & 93.1161 & 93.1161 \\
\hline $\mathrm{P}_{\mathrm{G} 4}(\mathrm{MW})$ & 77.9808 & 77.9810 & 86.5679 & 86.5682 & 90.1319 & 90.1319 \\
\hline $\mathrm{P}_{\mathrm{GS}}(\mathrm{MW})$ & 178.1666 & 178.1665 & 130.0002 & 130.000 & 143.6051 & 143.6048 \\
\hline $\mathrm{P}_{\mathrm{G} 6}(\mathrm{MW})$ & 154.9068 & 154.9065 & 125.0001 & 125.000 & 138.2971 & 138.2972 \\
\hline Total FC $(\$ / h)$ & $27,004.1$ & $27,004.1$ & $27,327.9$ & $27,327.9$ & $27,092.6$ & $27,092.6$ \\
\hline Emission $(\mathrm{kg} / \mathrm{h})$ & 281.919 & 281.918 & 255.346 & 255.346 & 261.134 & 261.134 \\
\hline Line losses (MW) & 0.00 & 0.00 & 0.00 & 0.00 & 0.00 & 0.00 \\
\hline Execution time (sec) & 4.632346 & 1.444066 & 2.738104 & 1.68603 & 3.246230 & 1.948214 \\
\hline
\end{tabular}

$\mathrm{FC}=$ Fuel Cost

Table 4: Optimal scheduling of 6-generator by using PS only and integrated GA-PS (losses are considered) with $\mathrm{P}_{\mathrm{Demand}}=500 \mathrm{MW}$

\begin{tabular}{|c|c|c|c|c|c|c|}
\hline \multirow[b]{2}{*}{ Unit/Study mode } & \multicolumn{2}{|c|}{ Best fuel $(W=1)$} & \multicolumn{2}{|c|}{ Best emission $(W=0)$} & \multicolumn{2}{|c|}{ CEED $(W=0.5)$} \\
\hline & PS & GA-PS & PS & GA-PS & PS & GA-PS \\
\hline $\mathrm{P}_{\mathrm{G} 1}(\mathrm{MW})$ & 19.4908 & 19.4910 & 38.1786 & 38.1785 & 21.7063 & 21.7063 \\
\hline $\mathrm{P}_{\mathrm{G} 2}(\mathrm{MW})$ & 10.0000 & 10.0000 & 38.9995 & 38.9998 & 17.8420 & 17.8420 \\
\hline $\mathrm{P}_{\mathrm{G} 3}(\mathrm{MW})$ & 72.6320 & 72.6317 & 88.0878 & 88.0876 & 95.1107 & 95.1107 \\
\hline $\mathrm{P}_{\mathrm{G} 4}(\mathrm{MW})$ & 82.8055 & 82.8055 & 87.8587 & 87.8589 & 91.4427 & 91.4425 \\
\hline $\mathrm{P}_{\mathrm{GS}}(\mathrm{MW})$ & 175.1911 & 175.1910 & 130.0001 & 130.000 & 144.4177 & 144.4179 \\
\hline $\mathrm{P}_{\mathrm{G} 6}(\mathrm{MW})$ & 149.7663 & 149.7666 & 125.5378 & 125.5378 & 138.7052 & 138.7053 \\
\hline Total FC (\$/h) & $27,443.2$ & $27,443.2$ & $27,755.2$ & $27,755.2$ & $27,519.4$ & $27,519.4$ \\
\hline Emission $(\mathrm{kg} / \mathrm{h})$ & 281.751 & 281.752 & 260.912 & 260.912 & 266.736 & 266.737 \\
\hline Line losses (MW) & 9.88579 & 9.8858 & 8.66256 & 8.66255 & 9.22467 & 9.22468 \\
\hline Execution time (sec) & 4.077829 & 1.422702 & 2.622771 & 1.733114 & 2.869270 & 1.449194 \\
\hline
\end{tabular}

Table 5: CEED comparison of fuel cost $(\$ / \mathrm{h})$ for 6-Generator System (No losses)

\begin{tabular}{|c|c|c|c|c|c|c|}
\hline$\underline{P}_{\text {Demand }}$ & $\begin{array}{l}\text { Muralidharan et al. } \\
(2006) \text {; recursive }\end{array}$ & $\begin{array}{l}\text { Balamurugan and } \\
\text { Subramanian (2007); } \\
\text { simplified recursive }\end{array}$ & $\begin{array}{c}\text { Sasikala and } \\
\text { Ramaswamy } \\
(2010) ; \mathrm{SA}\end{array}$ & $\begin{array}{c}\text { Guvenc } \\
(2010) ; \mathrm{GA}\end{array}$ & $\begin{array}{c}\text { Proposed } \\
\text { PS }\end{array}$ & $\begin{array}{c}\text { Proposed } \\
\text { GA-PS }\end{array}$ \\
\hline 500 & $27,092.46$ & $27,092.46$ & $27,092.42$ & $27,089.45$ & $27,092.6$ & $27,092.6$ \\
\hline 600 & $31,628.64$ & $31,628.63$ & $31,628.63$ & $31,626.79$ & $31,628.6$ & $31,628.6$ \\
\hline 700 & $36,313.94$ & $36,313.92$ & $36,313.92$ & $36,310.80$ & $36,313.9$ & $36,313.9$ \\
\hline 800 & $41,148.33$ & $41,148.32$ & $41,148.31$ & $41,144.47$ & $41,148.2$ & $41,148.2$ \\
\hline 900 & $46,131.85$ & $46,131.87$ & $46,131.86$ & $46,124.54$ & $46,131.8$ & $46,131.8$ \\
\hline 1000 & $51,264.49$ & $51,264.47$ & $51,264.41$ & $51,262.31$ & $51,264.5$ & $51,264.5$ \\
\hline
\end{tabular}


Int. J. Soft Comput., 7 (5): 256-263, 2012

Table 6: CEED comparison of emission ( $\mathrm{kg} / \mathrm{h}$ ) for 6-Generator Sy stem (No losses)

\begin{tabular}{lcccccc}
\hline Muralidharan et al. & $\begin{array}{c}\text { Balamurugan and } \\
\text { Subramanian (2007); } \\
\text { simplified recursive }\end{array}$ & $\begin{array}{c}\text { Sasikala and } \\
\text { Ramaswamy } \\
(2010) ; \text { SA }\end{array}$ & $\begin{array}{c}\text { Guvenc } \\
(2010) ; \text { GA }\end{array}$ & $\begin{array}{c}\text { Proposed } \\
\text { PS }\end{array}$ & $\begin{array}{c}\text { Proposed } \\
\text { GA-PS }\end{array}$ \\
\hline 500 & 261.63 & 261.63 & 261.63 & 261.3307 & 261.134 & 261.134 \\
600 & 338.99 & 338.99 & 338.99 & 338.4397 & 338.321 & 338.321 \\
700 & 434.38 & 434.38 & 434.38 & 433.6409 & 433.510 & 433.510 \\
800 & 547.80 & 547.80 & 547.79 & 546.7831 & 546.700 & 546.700 \\
900 & 679.24 & 679.24 & 679.24 & 678.2906 & 677.892 & 677.892 \\
1000 & 828.72 & 828.72 & 828.71 & 827.2612 & 827.086 & 827.086 \\
\hline
\end{tabular}

Table 7: Generating units fuel cost coefficients (valve-effect coefficients are neglected) and generation operation limits

\begin{tabular}{lccccc}
\multicolumn{6}{c}{ neglected) and generation operation limits } \\
\hline Units & $\begin{array}{c}\mathrm{a}_{\mathrm{i}} \\
\left(\$ /\left(\mathrm{MW}^{2} \mathrm{~h}\right)\right)\end{array}$ & $\begin{array}{c}\mathrm{b}_{\mathrm{i}} \\
(\$ /(\mathrm{MWh}))\end{array}$ & $\begin{array}{c}\mathrm{c}_{\mathrm{i}} \\
(\$ / \mathrm{h})\end{array}$ & $\begin{array}{c}\mathrm{P}_{\text {, } \min } \\
(\mathrm{MW})\end{array}$ & $\begin{array}{c}\mathrm{P}_{\mathrm{i} \text { max }} \\
(\mathrm{MW})\end{array}$ \\
\hline $\mathrm{G}_{1}$ & 0.00762 & 1.92699 & 387.85 & 20 & 250 \\
$\mathrm{G}_{2}$ & 0.00838 & 2.11969 & 441.62 & 20 & 210 \\
$\mathrm{G}_{3}$ & 0.00523 & 2.19196 & 422.57 & 20 & 250 \\
$\mathrm{G}_{4}$ & 0.00140 & 2.01983 & 552.50 & 60 & 300 \\
$\mathrm{G}_{5}$ & 0.00154 & 2.22181 & 557.75 & 20 & 210 \\
$\mathrm{G}_{6}$ & 0.00177 & 1.91528 & 562.18 & 60 & 300 \\
$\mathrm{G}_{7}$ & 0.00195 & 2.10681 & 568.39 & 20 & 215 \\
$\mathrm{G}_{8}$ & 0.00106 & 1.99138 & 682.93 & 100 & 455 \\
$\mathrm{G}_{9}$ & 0.00117 & 1.99802 & 741.22 & 100 & 455 \\
$\mathrm{G}_{10}$ & 0.00089 & 2.12352 & 617.83 & 110 & 460 \\
$\mathrm{G}_{11}$ & 0.00098 & 2.10487 & 674.61 & 110 & 465 \\
\hline
\end{tabular}

Table 8: Emission coefficients of 11-Generator System

\begin{tabular}{lccc}
\hline Units & $\alpha_{\mathrm{I}}\left(\mathrm{kg} /\left(\mathrm{MW}^{2} \mathrm{~h}\right)\right)$ & $\beta_{\mathrm{i}}(\mathrm{kg} /(\mathrm{MWh}))$ & $\gamma_{\mathrm{i}}(\mathrm{kg} / \mathrm{h})$ \\
\hline $\mathrm{G}_{1}$ & 0.00419 & 0.67767 & 33.93 \\
$\mathrm{G}_{2}$ & 0.00461 & 0.69044 & 24.62 \\
$\mathrm{G}_{3}$ & 0.00419 & 0.67767 & 33.93 \\
$\mathrm{G}_{4}$ & 0.00683 & 0.54551 & 27.14 \\
$\mathrm{G}_{5}$ & 0.00751 & 0.40060 & 24.15 \\
$\mathrm{G}_{6}$ & 0.00683 & 0.54551 & 27.14 \\
$\mathrm{G}_{7}$ & 0.00751 & 0.40006 & 24.15 \\
$\mathrm{G}_{8}$ & 0.00355 & 0.51116 & 30.45 \\
$\mathrm{G}_{9}$ & 0.00417 & 0.56228 & 25.59 \\
$\mathrm{G}_{10}$ & 0.00355 & 0.41116 & 30.45 \\
$\mathrm{G}_{11}$ & 0.00417 & 0.56228 & 25.59 \\
\hline
\end{tabular}

time to get solutions using a combination of GA-PS is $1.69 \mathrm{sec}$ on average which is very low compared with (Sasikala and Ramaswamy, 2010).

Case 2: 11-Generating Unit's System no line losses: In order to demonstrate the efficiency and the robustness of the proposed algorithms, an 11-Generator System is considered with data given as shown in Table 7 and 8 . The results of the proposed and other four methods are shown in Table 9-11 for best fuel costs in $\$ / h$ and emission rate in $\mathrm{kg} / \mathrm{h}$, respectively with relaxing all equality and inequality constraints. Figure 3 shows the mesh size throughout the convergence process of Integrated GA-PS. It is apparent that the mesh size decreases until the algorithm terminates in this case at a mesh size of $9.5367 \times 10^{-7}$ in $2.62 \mathrm{sec}$ in $<100$ iterations. However, the convergence with PS only, at mesh size of $9.5367 \times 10^{-7}$ with execution time of $7.41 \mathrm{sec}$ in 370 iterations as shown in Fig. 4. The normalized execution

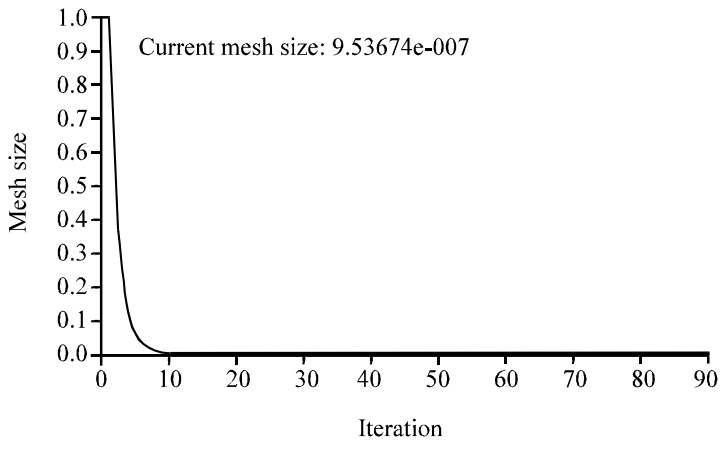

Fig. 3: Convergence graph for 11-units-case of $2500 \mathrm{MW}$ power demand with GA-PS

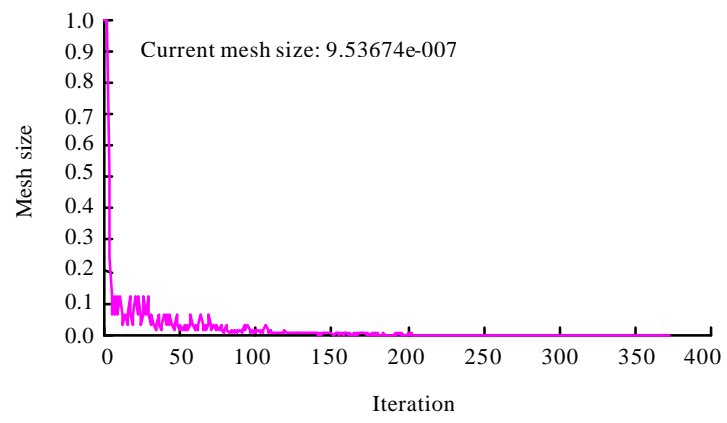

Fig. 4: Convergence graph for 11-units-case of $2500 \mathrm{MW}$ power demand with PS only

time of SA method reported by Sasikala and Ramaswamy (2010) is $28.45 \mathrm{sec}$ for 11 -Unit System which is very high compared to the proposed GA-PS hybrid approaches which is on average of $2.44 \mathrm{sec}$.

It is obvious that the proposed methods produced very competitive solutions with a smaller search for 6 and 11 Generator Systems at the global optimal solution in very fast normalized execution time. Generally, both PS and proposed integrated GA-PS are able to obtain global or near global optimal solutions with competitive results. However, the execution time of proposed GA-PS is dramatically improved with this combination. For GA, no need to pay more effort on tuning the GA parameters as usual, only initial point is required for PS. 
Int. J. Soft Comput., 7 (5): 256-263, 2012

Table 9: Optimal scheduling of 11-generator by PS only and integrated GA-PS (No losses) with study mode of CEED

\begin{tabular}{|c|c|c|c|c|c|c|}
\hline \multirow[b]{2}{*}{ Units } & \multicolumn{2}{|c|}{$P_{D}=1000 \mathrm{MW}$} & \multicolumn{2}{|c|}{$P_{D}=1500 M W$} & \multicolumn{2}{|c|}{$P_{D}=2000 \mathrm{MW}$} \\
\hline & PS & GA-PS & PS & GA-PS & PS & GA-PS \\
\hline $\mathrm{P}_{\mathrm{G} 1}(\mathrm{MW})$ & 85.60571 & 85.60589 & 103.62813 & 103.62806 & 121.65040 & 121.65025 \\
\hline $\mathrm{P}_{\mathrm{G} 2}(\mathrm{MW})$ & 76.67308 & 76.67290 & 88.70901 & 88.70881 & 100.74485 & 100.74481 \\
\hline $\mathrm{P}_{\mathrm{G} 3}(\mathrm{MW})$ & 87.25848 & 87.25840 & 106.77278 & 106.77292 & 126.28760 & 126.28763 \\
\hline $\mathrm{P}_{\mathrm{G} 4}(\mathrm{MW})$ & 78.49479 & 78.49472 & 126.17199 & 126.17216 & 173.84996 & 173.84921 \\
\hline $\mathrm{P}_{\mathrm{GS}}(\mathrm{MW})$ & 47.91502 & 47.91572 & 77.53466 & 77.53494 & 107.15409 & 107.15443 \\
\hline $\mathrm{P}_{\mathrm{G} 6}(\mathrm{MW})$ & 79.32480 & 79.32483 & 125.74205 & 125.74242 & 172.16049 & 172.16013 \\
\hline $\mathrm{P}_{\mathrm{G} 7}(\mathrm{MW})$ & 49.76554 & 49.76542 & 79.93089 & 79.93057 & 110.09568 & 110.09573 \\
\hline $\mathrm{P}_{\mathrm{G} 8}(\mathrm{MW})$ & 129.60363 & 129.60347 & 201.41723 & 201.41799 & 273.23278 & 273.23184 \\
\hline $\mathrm{P}_{\mathrm{Gg}}(\mathrm{MW})$ & 122.36940 & 122.37023 & 191.40796 & 191.40825 & 260.44515 & 260.44576 \\
\hline $\mathrm{P}_{\mathrm{G} 10}(\mathrm{MW})$ & 119.60012 & 119.59961 & 200.94849 & 200.94816 & 282.29702 & 282.29663 \\
\hline $\mathrm{P}_{\mathrm{G} 11}(\mathrm{MW})$ & 123.38944 & 123.38880 & 197.73680 & 197.73572 & 272.08197 & 272.08359 \\
\hline Total FC (\$/h) & $8,502.290$ & $8,502.290$ & $9,733.540$ & $9,733.540$ & $11,041.10$ & $11,041.10$ \\
\hline Emission $(\mathrm{kg} / \mathrm{h})$ & 205.204 & 205.204 & 540.544 & 540.544 & $1,139.91$ & $1,139.91$ \\
\hline Execution time (sec) & 7.607189 & 2.952258 & 7.784215 & 1.798952 & 8.265827 & 2.560709 \\
\hline
\end{tabular}

Table 10: CEED comparison of fuel cost $(\$ h)$ for 11-Generator System (No losses)

\begin{tabular}{lcccrcr}
\hline & $\begin{array}{c}\text { Balamurugan and } \\
\mathrm{P}_{\text {Demand }}\end{array}$ & $\begin{array}{c}\text { Sasikala and } \\
\text { Ramaswamy } \\
(2006) ; \text { recursive }\end{array}$ & $\begin{array}{c}\text { Subramanian (2007); } \\
\text { simplified recursive }\end{array}$ & $\begin{array}{c}\text { Guvenc } \\
(2010) ; \mathrm{SA}\end{array}$ & $\begin{array}{c}\text { Proposed } \\
\text { (2010); GA }\end{array}$ & $\begin{array}{c}\text { Proposed } \\
\text { GA-PS }\end{array}$ \\
1000 & $8,502.29$ & $8,502.29$ & $8,502.30$ & $8,501.85$ & $8,502.29$ & $8,502.29$ \\
1500 & $9,733.54$ & $9,733.54$ & $9,733.53$ & $9,733.22$ & $9,733.54$ & $9,733.54$ \\
1750 & $10,377.77$ & $10,377.77$ & $10,377.78$ & $10,377.01$ & $10,377.8$ & $10,377.8$ \\
2000 & $11,041.08$ & $11,041.08$ & $11,041.09$ & $11,040.84$ & $11,041.1$ & $11,041.1$ \\
2500 & $12,424.94$ & $12,424.94$ & $12,424.94$ & $12,423.77$ & $12,424.9$ & $12,424.9$ \\
\hline
\end{tabular}

Table 11: CEED comparison of emission ( $\mathrm{kg} / \mathrm{h}$ ) for 11-Generator System (No losses)

\begin{tabular}{lcccrrr}
\hline & $\begin{array}{c}\text { Muralidharan } \text { et al. } \\
(2006) ; \text { recursive }\end{array}$ & $\begin{array}{c}\text { Balamurugan and } \\
\text { Subramanian (2007); } \\
\text { simplified recursive }\end{array}$ & $\begin{array}{c}\text { Kumarappan } \text { et al. } \\
(2002) ; \text { SA }\end{array}$ & $\begin{array}{c}\text { King } \text { et al. } \\
(1995) ; \text { GA }\end{array}$ & $\begin{array}{c}\text { Proposed } \\
\text { PS }\end{array}$ & $\begin{array}{c}\text { Proposed } \\
\text { GA-PS }\end{array}$ \\
\hline 1000 & 205.20 & 205.20 & 205.20 & 205.175 & 205.204 & 205.204 \\
1500 & 540.54 & 540.54 & 540.54 & 539.493 & 540.544 & 540.544 \\
1750 & 807.22 & 807.22 & 807.23 & 807.214 & 807.224 & 807.224 \\
2000 & $1,139.91$ & $1,139.91$ & $1,139.91$ & $1,138.279$ & $1,139.91$ & $1,139.91$ \\
2500 & $2,003.30$ & $2,003.30$ & $2,003.30$ & $2,003.030$ & $2,003.31$ & $2,003.31$ \\
\hline
\end{tabular}

\section{CONCLUSION}

In this study, a weighting multi-objective function for environmental economic dispatching is proposed. The proposed objective function is optimized based on the proposed integration of GA and PS algorithms with comparative of the obtained results and time of calculations. The proposed solution algorithm is applied on 6 and 11 Generation Test Systems. The results showed that sets of suitable dispatch with respect to economic, emission or combined objectives can be efficiently found. Many others conditions and constraints were also observed and sustained such as load balance, generator's operation limits, valve-point loading effects and network line losses. The proposed algorithm has been demonstrated to perform well when applied to solve ELD, $\mathrm{EmD}$ and CEED problems.

PS proceeds with only one candidate solution all the time and therefore does not build up an overall view of the search space. Accordingly, high-quality results cannot be obtained by distinct algorithm within a reasonable time. Therefore, combining two or more algorithms in order to improve solution quality and reduce execution time may be achieved in most of optimization problems. The obtained results are compared with the results of other algorithms. The results show the ability of the proposed algorithm to reduce the running time compared with the other methods at the same level of accuracy.

\section{REFERENCES}

Abido, M.A., 2003. Environmental/economic power dispatch using multiobjective evolutionary algorithms. IEEE Trans. Power Syst., 18: 1529-1537.

Abido, M.A., 2006. Multi-objective evolutionary algorithms for electric power dispatch problem. IEEE Trans. Evol. Comput., 10: 315-329.

Al-Sumait, J.S., A.K. Al-Othman and J.K. Sykulski, 2007. Application of Pattern Search method to power system valve-point economic load dispatch. Electr. Power Energy Syst., 29: 720-730.

Anonymous, 1991. Canada/nova scotia agreement respecting an acid rain reduction program nova scotia 1991 annual report. Department of the Environment, Nova Scotia, pp: 67. 
Audet, C. and J.E. Dennis Jr., 2003. Analysis of generalized pattern searches. SIAM J. Optim., 13: $889-903$.

Balamurugan, R. and S. Subramanian, 2007. A simplified recursive approach to combined economic emission dispatch. Electr. Power Compon. Syst., 36: 17-27.

Bansal, R.C., 2005. Optimization methods for electric power systems: An overview. Int. J. Emerg. Electr. Power Syst., 2: 1-23.

Basu, M., 2005. A simulated annealing-based goalattainment method for economic emission load dispatch of fixed head hydrothermal power systems. Electric. Power Energy Syst., 27: 147-153.

Basu, M., 2007. Dynamic economic emission dispatch using evolutionary programming and fuzzy satisfying method. Int. J. Emerg. Electric. Power Syst., Vol. 8. 10.2202/1553-779X.1146.

Chaturvedi, K.T., M. Pandit and L. Srivastava, 2008. Environmental economic dispatch using multiobjective particle swarm optimization technique with fuzzy decision making. Proceedings of the 32th National Systems Conference, December 17-19, 2008, Department of Electrical Engineering, Roorkee, India, pp: 548-553.

Gent, M.R. and J.W. Lamont, 1971. Minimum-emission dispatch. IEEE Trans. Power Apparatus Syst., PAS90: 2650-2660.

Goodman, E.D., 2007. Introduction to genetic algorithms. Proceedings of the GECCO Conference Companion on Genetic and Evolutionary Computation, July 7-11, 2007, London, UK., pp: 3205-3224.

Guvenc, U., 2010. Combined economic emission dispatch solution using genetic algorithm based on similarity crossover. Scient. Res. Essays, 5: 2451-2456.

King, R.T.F., H.C.S. Rughooputh and K. Deb, 2006. Stochastic evolutionary multi-objective environmental/economic dispatch. Proceedings of the IEEE Congress on Evolutionary Computation, July 16-21, 2006, Vancouver, BC, Canada, pp: 946-953.

King, T.D., M.E. El-Hawary and F. El-Hawary, 1995. Optimal environmental dispatching of electric power systems via an improved hopfield neural network model. IEEE Trans. Power Syst., 10: 1559-1565.

Kolda, T.G., R.M. Lewis and V. Torczon, 2003. Optimization by direct search: New perspectives on some classical and modern methods. SIAM Rev., 45: $385-482$

Kumarappan, N., M.R. Mohan and S. Murugappan, 2002. Ann approach applied to combined economic and emission dispatch for large- scale system. Proceedings of the International Joint Conference on Neural Networks, Volume 1, May 12-17, 2002, Honolulu, HI., USA., pp: 323-327.
Lee, K.Y. and M.A. El-Sharkawi, 2008. Modern Heuristic Optimization Techniques: Theory and Applications to Power Systems. John Wiley and Sons, New York, USA., ISBN: 978-0471-45711-4, Pages: 586.

Mitchell, M., 1998. An Introduction to Genetic Algorithms. The MT Press, USA., ISBN-10: 0262631857, Page: 221.

Muralidharan, S., K. Srikrishna and S. Subramanian, 2006. Emission constrained economic dispatch-a new recursive approach. Electric Power Compon. Sys., 34: 343-353.

Pao-La-Or, P., A. Oonsivilai and T. Kulworawanichpong, 2010. Combined economic and emission dispatch using particle swarm optimization. Wseas Trans. Environ. Dev., 6: 296-305.

Pitono, J., A. Soeprijanto and T. Hiyama, 2009. Hybrid optimization of emission and economic dispatch by the sigmoid decreasing inertia weight particle swarm optimization. World Acad. Sci. Eng. Technol., 60: $315-320$.

Sasikala, J. and M. Ramaswamy, 2010. Optimal $\lambda$ based economic emission dispatch using simulated annealing. Int. J. Comput. Appli., 1: 55-65.

Senthil, K. and K. Manikandan, 2010. Improved tabu search algorithm to economic emission dispatch with transmission line constraint. Int. J. Comput. Sci. Commun., 1: 145-149.

Song, Y.H., G.S. Wang, P.Y. Wang and A.T. Johns, 1997. Environmental economic dispatch using fuzzy logic controlled genetic algorithms. IEEE Proc. Gen. Transm. Distrib., 144: 377-382.

Talaq, J.H., F. El-Hawary and M.E. El-Hawary, 1994. A summary of environmental/economic dispatch algorithms. IEEE Trans. Power Syst., 9: 1508-1516.

Thakur, T., K. Sem, S. Saini and S. Sharma, 2006. A particle swarm optimization solution to $\mathrm{NO}_{2}$ and $\mathrm{SO}_{2}$ emissions for environmentally constrained economic dispatch problem. Proceedings of the IEEE/PES Transmission and Distribution Conference and Exposition, August 15-18, 2006, Latin America, pp: $1-5$.

Venkatesh, P., R. Gnanadass and N.P. Padhy, 2003. Comparison and application of evolutionary programming techniques to combined economic emission dispatch with line flow constrained. IEEE. Trans. Power Syst., 18: 688-697.

Yokoyama, R., S.H. Bae, T. Morita and H. Sasaki, 1988. Multi-objective optimal generation dispatch based on probability security criteria. IEEE Tran. Power Syst., 3: $317-324$.

Zhu, J., 2009. Optimization of Power System Operation. John Wiley and Sons, New York, USA., ISBN: 978-0470-29888-6, Pages: 603. 